\title{
CORRESPONDENCE
}

\section{RULES OF NOMENCLATURE}

SIR,-W. J. Arkell (Geol. Mag., 1954, 91, p. 174: Jour. Paleont., 1954, 28 , no. 2, p. 218) has recently attacked clause $54(1)(a)$ of the "Copenhagen Decisions on Zoological Nomenclature ", which provides that a change in the name of a type genus because of synonymy, whether objective or subjective, will not necessitate a change in any family-group name founded upon it. The purpose of this decision was to provide greater stability and continuity to names of the family group, especially those of families and superfamilies that are of wide and general usefulness and importance. It is accordingly surprising to find such a worthwhile provision so vehemently opposed. If, indeed, the decision would produce " unhappy effects" and " completely unfamiliar monstrosities", and if it would result in a "discreditable hunt ... to be first to unearth these corpses [junior synonyms] for revival ", I am sure that those of us who warmly supported it at Copenhagen would join Dr. Arkell in denouncing it. But it seems clear that Dr. Arkell has misread the decision and has misjudged its effects. It is to be hoped that his forceful language has not prejudiced the case.

(1) The Copenhagen decision actually reads " where the name of the type genus ... has to be changed because it is found to be ... [a junior synonym] ", and not, as Dr. Arkell gives it, where it " has been changed because it is ....". His fears of the ghosts of long-buried junior synonyms are understandable if one begins with his verb tenses, but not with those adopted at the Congress. Clause $54(1)(a)$ as it stands is specifically designed to avoid changes in the future. A procedure that can be applied to the past is given in clause 45 , which Dr. Arkell does not mention.

(2) Under the old Code, when the type genus was found to be a junior synonym, both generic and group names had to be changed, including those of tribe, subfamily, family, and superfamily, if all were involved. Changes in at least the higher group names usually had wide repercussions in unfamiliarity and inconvenience in collateral fields and in teaching. Under the Copenhagen plan, when such synonymy occurs, the rule will not require any changes of family-group names. This will give consequent advantages in stability, continuity, and familiarity. Under Dr. Arkell's proposal, however, we would revert to the old Code, under which changes would be required in those cases. We would be forced in the future to change family-group names to those new and hence "completely unfamiliar" group names which he himself dislikes. Furthermore, in cases of subjective synonymy, we might have to change names frequently, in keeping pace with changing subjective views of authors.

(3) Even if Dr. Arkell's interpretation were correct, authors who wished to avoid exhuming old group names based on long-buried junior synonyms would have only to maintain current usage while following the procedure provided in clause 45 . Surely it is a mistake to lift clause 54 (1) (a) out of the plan and criticize it without relation to other provisions, especially those of clauses 45 and 54 (2).

(4) It should be noted that the views of Dr. Arkell, and also those of Dr. R. C. Moore, the leader of the Treatise of Paleontology currently in progress, were published in the Bulletin of Zoological Nomenclature prior to the Copenhagen meeting, along with many other expressions of opinion and arguments pro and con. All of these were before the Copenhagen Colloquium, which considered the problem in detail and recommended the plan on familygroup names to the Commission and thence to the Section on Nomenclature and the Congress. Paleontologists were represented at all stages, and the views of Arkell, Moore, and others were known and their viewpoints argued. There was, of course, difference of opinion on this point, as there was on many points. But the decision in clause $54(1)(a)$ was arrived at by the substantial majority of 20 to 8 after lengthy discussion of the advantages and disadvantages, on the first and least hurried day of the Colloquium, and

vol. XCI. -No. 4 
under the best circumstances in which nomenclatural decisions have ever been taken.

In England, more than twenty-five years ago, the British National Committee on Entomological Nomenclature formally proposed that a family name was not to be changed unless it or the name of its type genus was found to be a homonym. That Committee included such well known zoologists as Karl Jordan, S. A. Neave, and G. A. K. Marshall. Support for this solution of the problem has been growing in the last decade, and those who now wish to repeal it should realize the large amount of opinion on the other side. In the Bulletin of Zoological Nomenclature for July, 1953 (vol. 8, nos. 6/9), in which were published the views of Arkell and Moore, there are a number of statements in favour of not changing family names in cases of generic synonymy. The proposition of not changing was supported by several groups which gave special consideration to the major problems to come before the Copenhagen Congress-namely, the Nomenclature Committee of the Society of Systematic Zoology (W. I. Follett, Chairman: six out of eight members clearly expressing support), the American Committee on Entomological Nomenclature (C. D. Michener, Chairman), the Committee on Nomenclature of the American Museum of Natural History (John T. Zimmer, Chairman), and the Nomenclature Discussion Group of Washington, D.C. (R. E. Blackwelder, Secretary: approved by nearly two to one majority). Paleontologists are represented in three of those four groups. In a specialized field, the insect order Diptera, a questionnaire sent to dipterists all over the world in 1952 showed 69 per cent of 166 votes in favour of the solution as later adopted at Copenhagen. It thus appears that the Copenhagen vote was a fair sample of the views of zoologists.

(5) In the long view, if a great proportion of animal species remains to be discovered and named (estimates for neozoology alone range from 50 to 90 per cent), the number of generic and group names yet to be proposed and shuffled about with successive classifications and reclassifications will be considerable. Any rule that will render some name changing unnecessary for the future, as does clause 54 (1) (a), will be a great boon and should not be discarded.

Curtis W. Sabrosky.

\section{Entomology Research Branch, Agriculture Research Service,} United States Department of Agriculture. June, 1954.

\section{THE CARIBBEAN "OLIGOCENE"}

SIR,-Dr. Stainforth's comments on my recent paper on the MioceneOligocene boundary, especially in so far as they affect the Caribbean region (Geol. Mag., xci, No. 2, pp. 175-6, 1954), suggest that he has missed the object of the paper. I am familiar with the selected references cited by Mr. Stainforth, as well as many more concerning the Central American region and many others dealing with marine Miocene and Oligocene faunas in other parts of the world: only a few selected recent papers having a fundamental bearing on the subject were quoted in my original paper probably for the same reason as Dr. Stainforth-because a comprehensive list would have been impracticable as it would fill a whole issue of this periodical.

A study of the more recent literature, referred to in part before, indicates that there is a growing school of workers who recognize that the upper part of the so-called "Oligocene" in the Caribbean region is probably of Lower Miocene age: this is the view that I fully endorse as a result of researches carried out in many parts of the world over a period of nearly thirty years. It is evident that two important and world-wide palaeontological changes are involved, one between the Eocene and the Oligocene, the other between the Oligocene and the Miocene, the latter occurring well below the so-called " Miocene/Oligocene" boundary as interpreted until recent years in the Caribbean region. Consequently, I am firmly convinced that the faunal 